\title{
Does fluoride influence oviposition of Anopheles stephensi in stored water habitats in an urban setting?
}

Shalu Thomas ${ }^{1 \dagger}$, Sangamithra Ravishankaran ${ }^{1 \dagger}$, N. A. Johnson Amala Justin ${ }^{1}$, Aswin Asokan ${ }^{1}$, T. Maria Jusler Kalsingh ${ }^{1}$, Manu Thomas Mathai ${ }^{2}$, Neena Valecha ${ }^{3}$ and Alex Eapen ${ }^{1 *}$

\begin{abstract}
Background: The physico-chemical characteristics of lentic aquatic habitats greatly influence mosquito species in selecting suitable oviposition sites; immature development, pupation and adult emergence, therefore are considerations for their preferred ecological niche. Correlating water quality parameters with mosquito breeding, as well as immature vector density, are useful for vector control operations in identifying and targeting potential breeding habitats.
\end{abstract}

Methods: A total of 40 known habitats of Anopheles stephensi, randomly selected based on a vector survey in parallel, were inspected for the physical and chemical nature of the aquatic environment. Water samples were collected four times during 2013, representing four seasons (i.e., ten habitats per season). The physico-chemical variables and mosquito breeding were statistically analysed to find their correlation with immature density of An. stephensi and also co-inhabitation with other mosquito species.

Results: Anopheles stephensi prefer water with low nitrite content and high phosphate content. Parameters such as total dissolved solids, electrical conductivity, total hardness, chloride, fluoride and sulfate had a positive correlation in habitats with any mosquito species breeding $(p<0.05)$ and also in habitats with An. stephensi alone breeding. Fluoride was observed to have a strong positive correlation with immature density of An. stephensi in both overhead tanks and wells.

Conclusion: Knowledge of larval ecology of vector mosquitoes is a key factor in risk assessment and for implementing appropriate and sustainable vector control operations. The presence of fluoride in potential breeding habitats and a strong positive correlation with An. stephensi immature density is useful information, as fluoride can be considered an indicator/predictor of vector breeding. Effective larval source management can be focussed on specified habitats in vulnerable areas to reduce vector abundance and malaria transmission.

Keywords: Physico-chemical factors, Breeding habitats, Anopheles stephensi, Fluoride

\section{Background}

Mosquitoes exploit almost all types of lentic aquatic environments for oviposition [1]. Immature Anopheles thrive in a variety of aquatic ecosystems, such as fresh, brackish

\footnotetext{
*Correspondence: alexeapen@yahoo.com

†Shalu Thomas and Sangamithra Ravishankaran contributed equally to this work

${ }^{1}$ IDVC Field Unit, National Institute of Malaria Research (ICMR), NIE Campus, 2nd Main Road, TNHB, Ayapakkam, Chennai 600 077, India Full list of author information is available at the end of the article
}

waters found in rural, coastal and urban areas. Water quality of breeding habitat is an important determinant of whether or not the female mosquitoes will lay their eggs and the resulting immature stages will successfully complete their development to adults [2]. Characteristics of aquatic habitats are reported to influence the preferences of oviposition, possibility of hatching, immature development, pupation, and adult emergence, thus specifying the niche of a mosquito species [3]. Consequently breeding habitat characteristics could influence adult productivity 
and if the mosquito is of epidemiological importance, it will have a strong impact on the disease transmission [4]. Selection of an appropriate aquatic medium for oviposition could be an innate behavioural characteristic of a mosquito species. What drives a mosquito to select its ovipositional site from an array of aquatic habitats is yet to be fully ascertained and this information would be of paramount importance for focussing intervention operations to target potential vector breeding habitats, thereby reducing manpower and expenditure.

Information on the physico-chemical properties of the breeding habitat, a potential key element for larval surveillance could help in the implementation of better vector control programmes. Effective larval source management (LSM) requires a thorough knowledge of the breeding ecology of the mosquito species, its ovipositional preference, spatial and temporal distribution of the breeding sites besides, physical, chemical and biological characteristics of the habitats. Physico-chemical characteristics of the mosquito breeding habitat such as $\mathrm{pH}$, optimum temperature, total suspended solids, total dissolved solids, electrical conductivity, have an impact on larval development and survival [5]. Furthermore, temperature, salinity, carbonates and nitrates have been shown to correlate with the presence or development of quality of Anopheles larvae in pools [6]. Physico-chemical parameters of Anopheles breeding habitats in Iran indicated that there was a significant relationship between water temperature, conductivity, total alkalinity, sulfate, chloride, and Anopheles species distribution and abundance [7].

Anopheles stephensi, the vector responsible for urban malaria in Chennai, India, breeds mainly in clean/clear water, such as overhead tanks, wells, cisterns, roof gutters, curing pits in construction sites, fountains and ornamental tanks. Besides other man-made habitats, such as barrels or drums, sumps or underground tanks, and plastic pots/containers also contributes to enhanced mosquito/vector breeding [8]. Quantifying water quality in Anopheles breeding habitats may give more insight into its breeding profile, particularly in urban settings. It was observed that a larger proportion of OHTs support breeding of An. stephensi, compared to wells and other breeding habitats. Nevertheless, it was unclear whether this difference was because of differences in the abiotic factor, such as water quality, or biotic, such as co-inhabitation of other mosquito species with the urban vector [8]. Since relatively little information is available on habitat selection and physico-chemical factors determining oviposition behaviour of An. stephensi in field settings, the present study aimed to find the relationship between the physico-chemical factors of breeding habitats, such as OHTs and wells, with the occurrence and abundance of An. stephensi, in a malarious area of Besant Nagar in
Chennai of Peninsular India, for effective vector monitoring and disease control strategy.

\section{Methods \\ Study site and sample collection}

Besant Nagar is a residential area with slums, on the seashore in southeastern Chennai $\left(13.0002^{\circ} \mathrm{N}, 80.2668^{\circ} \mathrm{E}\right)$, characterized by its meso-endemic, perennial transmission of malaria, predominantly Plasmodium vivax, by the Asiatic urban malaria vector, An. stephensi. In the present study, potential An. stephensi habitats, OHTs and wells were randomly selected from each season of our yearlong weekly study of 20 sentinel and 20 random sites conducted in parallel in the same area [8], to evaluate physico-chemical properties of the habitat and its relation to occurrence and abundance of mosquito breeding (Fig. 1).

A total of 40 habitats i.e., ten habitats (five OHTs and five wells) were randomly selected from each season of a longitudinal study carried out in parallel to check the breeding pattern of vector mosquitoes [8]. Water samples were collected four times during April 2013 to March 2014, representing four seasons: April (summer), July (pre-monsoon), December (winter), and February (post-monsoon).

Among the possible/measurable physico-chemical parameters, physical parameters, such as turbidity, electrical conductivity (EC), total dissolved solids (TDS), and chemical parameters, such as $\mathrm{pH}$, alkalinity, total hardness, nitrites, nitrates, chlorides, fluorides, sulfate biochemical oxygen demand (BOD) dissolved oxygen (DO), were selected for analysis, since they have been reported to have correlation with mosquito breeding $[7,9]$. The habitats were also observed for the presence or absence of direct sunlight or shade, colour, and temperature of water at the time of inspection. Habitat particulars such as whether they were perennial (water stored throughout the year), temporary (occasionally filled/retained depending on need), open (with gaps allowing entry of mosquitoes or completely mosquito-proofed leaving no gaps), were considered from a longitudinal study carried out in parallel [8]. Immature collection in wells were done using 'well nets' (conical drop nets $20 \mathrm{~cm}$ in diameter and $10 \mathrm{~cm}$ deep, that were lowered into the well on a string), while ladles with a volume of $250 \mathrm{~mL}$ were used for OHTs, performing four dips per sampling occasion [10-12]. Collected immatures were identified, scored instar-wise and immature density was calculated as the number of immature/dip [8]. Anopheles immatures were emerged and identified to the species level using standard morphological identification keys [13, 14]. The physical parameters such as habitat positivity for Anopheles immatures (presence or absence of Anopheles immatures 


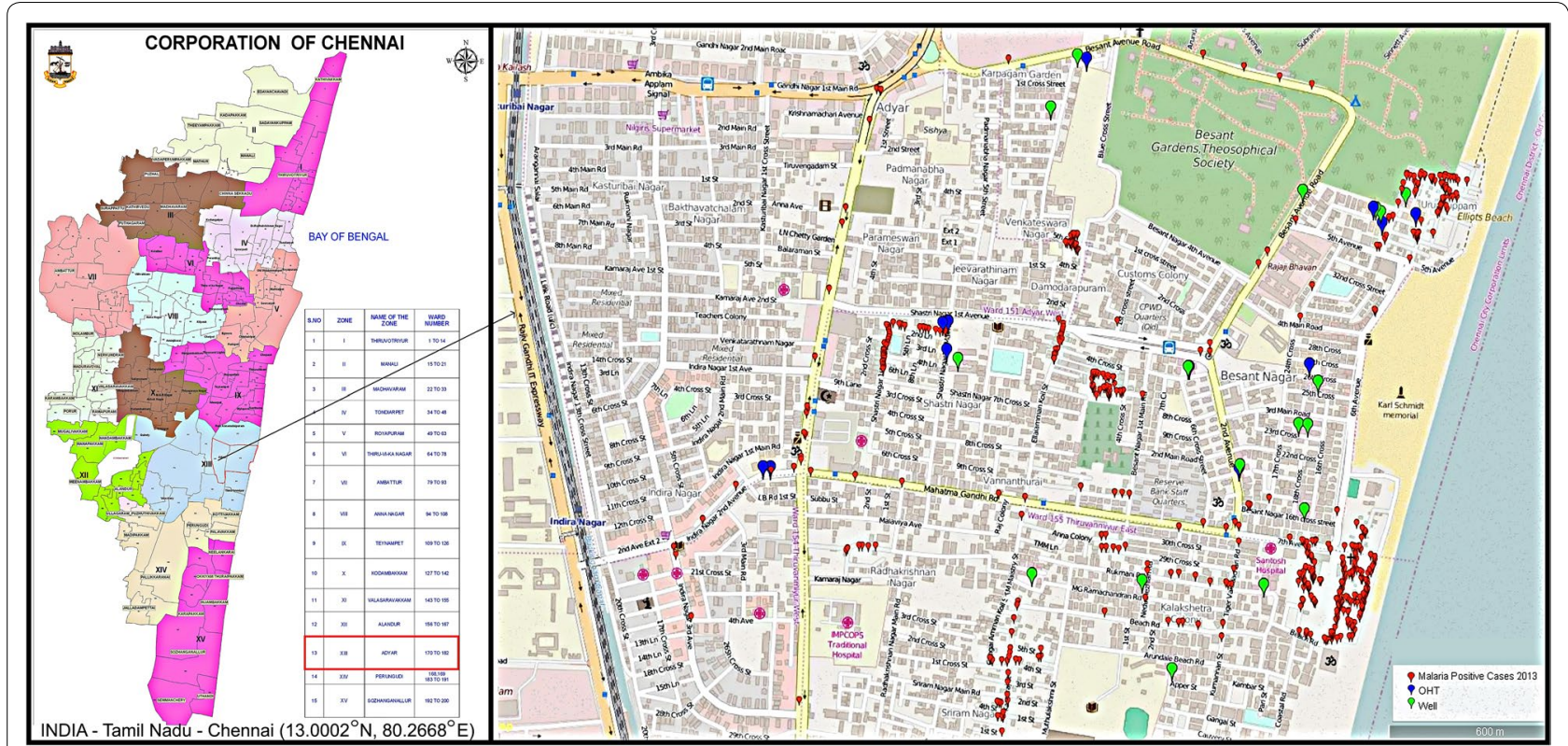

Fig. 1 Study area indicating malaria prevalence during 2013 and water sampling sites

in the habitat), immature count (instar-wise count of Anopheles larvae and pupal count), appearance of water (whether the water was clear or turbid), colour (whether the water seemed colourless or yellowish), sun/shade (whether the water in the habitat is exposed to direct sun or it is shaded by the presence of vegetation or any other covering), open/closed (whether the habitat is closed with a proper lid/covering which does not allow the entry of mosquito) were recorded on site by visual observation whereas temperature was measured using thermometer at the time of inspection. Turbidity, pH, TDS, EC and other chemical parameters were measured in a laboratory of Tamil Nadu Water Supply and Drainage Board (TWAD), Water Analysis Department, an ISO 9001: 2008 certified laboratory for 'Testing of physical, chemical \& bacteriological parameters for water \& waste water, testing of treatment chemicals and training in water analysis'.

Water was taken from middle of the source or habitat at mid-depth using a steel bucket of $3 \mathrm{~L}$ capacity for wells and a $250-\mathrm{mL}$ capacity dipper in the case of OHTs. The water was then carefully transferred to $2 \mathrm{~L}$ sample bottle consisting of an outer screw cap and an inner lid after rinsing with the water to be sampled. The sample bottle was filled to the brim without any air bubbles, labelled with date, time of collection, habitat type and location. They were then transported to the laboratory directly from the field site for immediate analysis. Water sampling was done as per standard sampling procedures and the physico-chemical parameters were analysed in the TWAD laboratory following the methods described by American Public Health Association [15]. The abiotic parameters were analysed based on the presence and absence of Anopheles immatures in the habitat at the time of inspection. The minimum, maximum and mean values of the parameters along with the standard deviation and range were calculated.

Student $t$ test was applied to find whether the physico-chemical parameters significantly differentiated the habitats with and without mosquito breeding. MannWhitney $U$ test was performed to find the significant difference of physico-chemical parameters between habitats where Anopheles bred alone and habitats where Anopheles were found co-inhabiting with other mosquitoes. Further, Pearson correlation was performed to find the correlation between immature density and physico-chemical parameters in habitats where Anopheles bred with other mosquitoes and with habitats where Anopheles bred alone, in wells and OHTs. In order to find the influence of all physico-chemical parameters on immature density, simple linear regression model was performed. Statistical analyses were done using SPSS software version 17 . The figures, which represent the scatter plot matrix of physico-chemical parameters with significant correlation, were generated using $\mathrm{R}$ software version 3.1. Institutional ethical clearance of the project was obtained (ECR/NIMR/EC/2010/100). 


\section{Results}

Mosquito breeding composition and immature density Immatures of $A n$. stephensi alone or in co-inhabitation with other mosquito species were found in 26 of the 40 habitats sampled. The habitats where An. stephensi were found alone were: 12 habitats (eight OHTs and four wells); There were ten habitats (nine wells and one OHT) with mixed population of Anopheles and Culex immatures; another habitat (one well) co-inhabited with An. stephensi and Aedes immatures; three habitats (two wells and one cistern) with mixed population of An. stephensi, Culex and Aedes immatures. Fourteen breeding habitats had no mosquito breeding at the time of inspection. The immature density of Anopheles species ranged from one to 31 per dip with $A n$. stephensi breeding alone. Anopheles + Culex co-inhabited habitats had one to 25 per dip, whereas in Anopheles + Aedes + Culex breeding habitats, the corresponding immature densities were three to ten per dip. The per-dip immature density in habitats with Anopheles + Aedes breeding was four. Though the objective of the study was to find any correlations between physico-chemical variables and An. stephensi, other mosquito species were also encountered while sampling. Anopheles subpictus was observed in OHTs and wells, whereas Culex quinquefasciatus, Culex gelidus and Aedes aegypti were the other species found in wells. All the habitats with open structures were located in shaded areas, except one which was directly exposed to sunlight. The water temperature ranged from 27 to $31{ }^{\circ} \mathrm{C}$ at the time of inspection.

\section{Comparison of physico-chemical parameters in habitats with and without mosquito breeding}

The physical and chemical parameters from the inspected habitats were analysed statistically (Table 1). The range of values for temperature, turbidity, $\mathrm{pH}$, and fluoride did not vary much among the habitats with and without mosquito breeding. However, the range of TDS, EC, total hardness, alkalinity, chloride, sulfate, BOD, and DO were found more in habitats with mosquito breeding compared to habitats without breeding, whereas a wider range of nitrate, nitrite and phosphate were found in those habitats without mosquito breeding.

The mean values of physical parameters, such as turbidity, TDS, total hardness, total alkalinity and EC besides chemical parameters, such as chloride, sulfate, BOD and DO values were higher in habitats with mosquito breeding compared to those without breeding. In habitats without mosquito breeding, the mean $\mathrm{pH}$ was found to be slightly acidic (6.6) whereas habitats with mosquito breeding exhibited alkaline $\mathrm{pH}$ (7.56), although both values were around the neutral $\mathrm{pH}(7)$. The mean values of phosphate, nitrite and nitrate were found to be comparatively higher in habitats without any mosquito breeding compared to those with breeding. When Student t-test was performed, it was observed that the mean value of nitrite was significantly higher in habitats without breeding of Anopheles species (Table 1) and the difference was statistically significant ( $\mathrm{p}=0.035)$.

Mann-Whitney $U$ test was performed to compare the selected parameters between two groups (Group A: habitats in which Anopheles bred alone, Group B:

Table 1 Physico-chemical parameters of habitats with and without mosquito breeding

\begin{tabular}{|c|c|c|c|c|}
\hline \multirow[t]{2}{*}{ Parameters } & \multicolumn{2}{|c|}{ Habitats with mosquito breeding $(n=26)$} & \multicolumn{2}{|c|}{$\begin{array}{l}\text { Habitats without mosquito breeding } \\
(n=14)\end{array}$} \\
\hline & Range & Mean \pm SD & Range & Mean \pm SD \\
\hline Temperature $\left({ }^{\circ} \mathrm{C}\right)$ & $27-30$ & $29.12 \pm 1.24$ & $27-31$ & $29 \pm 1.36$ \\
\hline Turbidity (NT) & $0.1-2.3$ & $0.61 \pm 0.61$ & $0.1-2.3$ & $0.64 \pm 0.57$ \\
\hline $\mathrm{TDS}(\mathrm{mg} / \mathrm{L})$ & $139-10,913$ & $1558.76 \pm 2820.86$ & $134-5480$ & $1304.14 \pm 1554.23$ \\
\hline EC (micromho/cm) & $198-15,590$ & $2386.03 \pm 4036.51$ & $192-7830$ & $1832.92 \pm 2238.86$ \\
\hline $\mathrm{pH}$ & $6.82-8.72$ & $7.56 \pm 0.5$ & $6.6-8.25$ & $6.6 \pm 0.51$ \\
\hline Total alkalinity (mg/L) & $60-760$ & $202.15 \pm 144.53$ & $45-280$ & $179.21 \pm 72.13$ \\
\hline Total hardness (mg/L) & $52-2800$ & $399.34 \pm 607.18$ & $64-1020$ & $352.71 \pm 338.3$ \\
\hline Nitrite (mg/L) & $0-1.21$ & $0.11 \pm 0.24$ & $0-3.81$ & $0.69 \pm 1.33$ \\
\hline Nitrate (mg/L) & $1-46$ & $12.57 \pm 13.62$ & $1-52$ & $19.14 \pm 19.3$ \\
\hline Chloride (mg/L) & $13-4800$ & $552.5 \pm 1247.98$ & $11-2500$ & $468.07 \pm 700.93$ \\
\hline Fluoride (mg/L) & $0-0.72$ & $0.22 \pm 0.18$ & $0.01-0.62$ & $0.22 \pm 0.18$ \\
\hline Sulfate (mg/L) & $1-310$ & $55.46 \pm 85.32$ & $0-231$ & $37.71 \pm 67.86$ \\
\hline Phosphate (mg/L) & $0-1.1$ & $0.34 \pm 0.29$ & $0-1.51$ & $0.48 \pm 0.4$ \\
\hline $\mathrm{BOD}(\mathrm{mg} / \mathrm{L})$ & $1.5-30$ & $6.22 \pm 6.83$ & $1-25$ & $5.96 \pm 6.64$ \\
\hline DO (mg/L) & $1.5-20$ & $4.13 \pm 3.53$ & $1.4-8$ & $3.61 \pm 1.94$ \\
\hline
\end{tabular}


Table 2 Analysis of physico-chemical parameters of habitats with Anopheles stephensi breeding

\begin{tabular}{|c|c|c|c|c|}
\hline \multirow[t]{3}{*}{ Parameters } & \multicolumn{4}{|c|}{ Breeding habitats } \\
\hline & \multicolumn{2}{|c|}{ Anopheles stephensi alone } & \multicolumn{2}{|c|}{$\begin{array}{l}\text { Anopheles stephensi with other mosquito } \\
\text { species }^{\mathrm{a}}\end{array}$} \\
\hline & Range & Mean \pm SD & Range & Mean \pm SD \\
\hline Temperature $\left({ }^{\circ} \mathrm{C}\right)$ & $27-30$ & $29.58 \pm 0.9$ & $27-30$ & $28.71 \pm 1.38$ \\
\hline Turbidity (NT) & $0.1-1.4$ & $0.46 \pm 0.48$ & $0.1-2.3$ & $0.75 \pm 0.69$ \\
\hline TDS (mg/L) & $174-10,913$ & $2579.17 \pm 3909.29$ & 139-3178 & $684.14 \pm 765.58$ \\
\hline EC (micromho/cm) & $248-15,590$ & $3687.25 \pm 5583.08$ & $198-4540$ & $1270.71 \pm 1433.76$ \\
\hline $\mathrm{pH}$ & $6.94-8.49$ & $7.52 \pm 0.53$ & $6.82-8.72$ & $7.59 \pm 0.5$ \\
\hline Total alkalinity (mg/L) & $60-440$ & $188.67 \pm 107.59$ & $72-760$ & $213.71 \pm 173.41$ \\
\hline Total hardness (mg/L) & $80-2800$ & $619 \pm 847.58$ & $52-600$ & $211.07 \pm 135.66$ \\
\hline Nitrite (mg/L) & $0-0.37$ & $0.1 \pm 0.15$ & $0-1.21$ & $0.13 \pm 0.31$ \\
\hline Nitrate (mg/L) & $1-46$ & $17.17 \pm 15.27$ & $1-41$ & $8.64 \pm 11.11$ \\
\hline Chloride (mg/L) & $18-4800$ & $1029 \pm 1744.64$ & $13-690$ & $144.07 \pm 174.38$ \\
\hline Fluoride (mg/L) & $0-0.44$ & $0.19 \pm 0.14$ & $0-0.72$ & $0.25 \pm 0.23$ \\
\hline Sulfate (mg/L) & $1-239$ & $71.33 \pm 91.12$ & $1-310$ & $41.86 \pm 80.9$ \\
\hline Phosphate (mg/L) & $0.07-1.1$ & $0.49 \pm 0.31$ & $0-0.82$ & $0.21 \pm 0.22$ \\
\hline $\mathrm{BOD}(\mathrm{mg} / \mathrm{L})$ & $2-10$ & $4.79 \pm 2.62$ & $1.5-30$ & $7.45 \pm 8.97$ \\
\hline DO (mg/L) & $1.5-6.2$ & $3.48 \pm 1.52$ & $1.6-20$ & $4.69 \pm 4.62$ \\
\hline
\end{tabular}

a Other mosquito species includes Anopheles subpictus, Culex quinquefasciatus, $C$. gelidus and Aedes aegypti

habitats in which Anopheles bred with other mosquito species). When these groups were compared, the mean value of phosphate was significantly higher in Group A $(0.49 \mathrm{mg} / \mathrm{L})$ than in Group B $(0.21 \mathrm{mg} / \mathrm{L})$ indicating higher phosphate content to favour Anopheles breeding but not with other mosquito species (Table 2).

\section{Correlations of physico-chemical parameters with immature density}

Pearson correlation was performed to analyse the effect of physico-chemical parameters on immature density of mosquito breeding habitats in general (Fig. 2a). It was found that TDS $(r=0.60)$, EC $(r=0.60)$, total hardness $(r=0.61)$, chloride $(r=0.60)$, sulfate $(r=0.41)$, and fluoride $(r=0.30)$ had significant positive correlation ( $\mathrm{p}<0.05)$. Further, when habitats with Anopheles breeding alone was considered, alkalinity $(\mathrm{r}=0.58)$ and nitrite $(r=0.65)$ along with the six parameters that had significant positive correlation with immature density in general, such as TDS $(r=0.86)$, EC $(r=0.82)$, total hardness $(r=0.89)$, chloride $(r=0.85)$, sulfate $(r=0.84)$, and fluoride $(r=0.85)$, comparatively had significantly strong positive correlation $(\mathrm{p}<0.05)$ whereas, temperature $(\mathrm{r}=0.82)$ had negative correlation (Fig. 2b).

When physico-chemical parameters of OHTs and wells were compared using Student $t$-test, it was found that parameters such as temperature, TDS, EC, alkalinity, total hardness, nitrite, nitrate, chloride, fluoride, sulfate, phosphate, and DO were significantly higher in OHTs $(\mathrm{p}<0.05)$. Further, when Pearson correlation was performed to explore the influence of the selected parameters on immature density in wells where An. stephensi bred alone, significant positive correlation of immature density with fluoride $(\mathrm{r}=0.97)$ and negative correlation $(\mathrm{p}<0.05)$ with $\mathrm{pH}(\mathrm{r}=0.99)$ was observed (Fig. 2c). Likewise, when the data was analysed for OHTs, the parameters TDS $(r=0.84)$, EC $(r=0.79)$, total hardness $(\mathrm{r}=0.87)$, chloride $(\mathrm{r}=0.82)$, fluoride $(\mathrm{r}=0.90)$, and sulfate $(\mathrm{r}=0.81)$ had positive correlation $(\mathrm{p}<0.05)$ with immature density, whereas temperature $(r=0.82)$ was negatively correlated (Fig. 2d).

\section{Effect of all physico-chemical parameters on immature density}

When linear regression model was performed to find the influence of all parameters together on An. stephensi immature density, multicollinearity problem was encountered. So, the variables (EC, Alkalinity total, Total hardness, Chloride, Sulfate) with high variance influence factor (VIF > 10) was removed and then the data was reanalysed which showed that fluoride, nitrite and TDS had significant influence on immature density (See Additional file 1: Table S1). Among the three significant parameters, fluoride has the highest regression coefficient value $(\beta=21.62)$. The model fit is $\mathrm{R}^{2}=0.91$ which means $91 \%$ of variance was exhibited by this model. Regression 


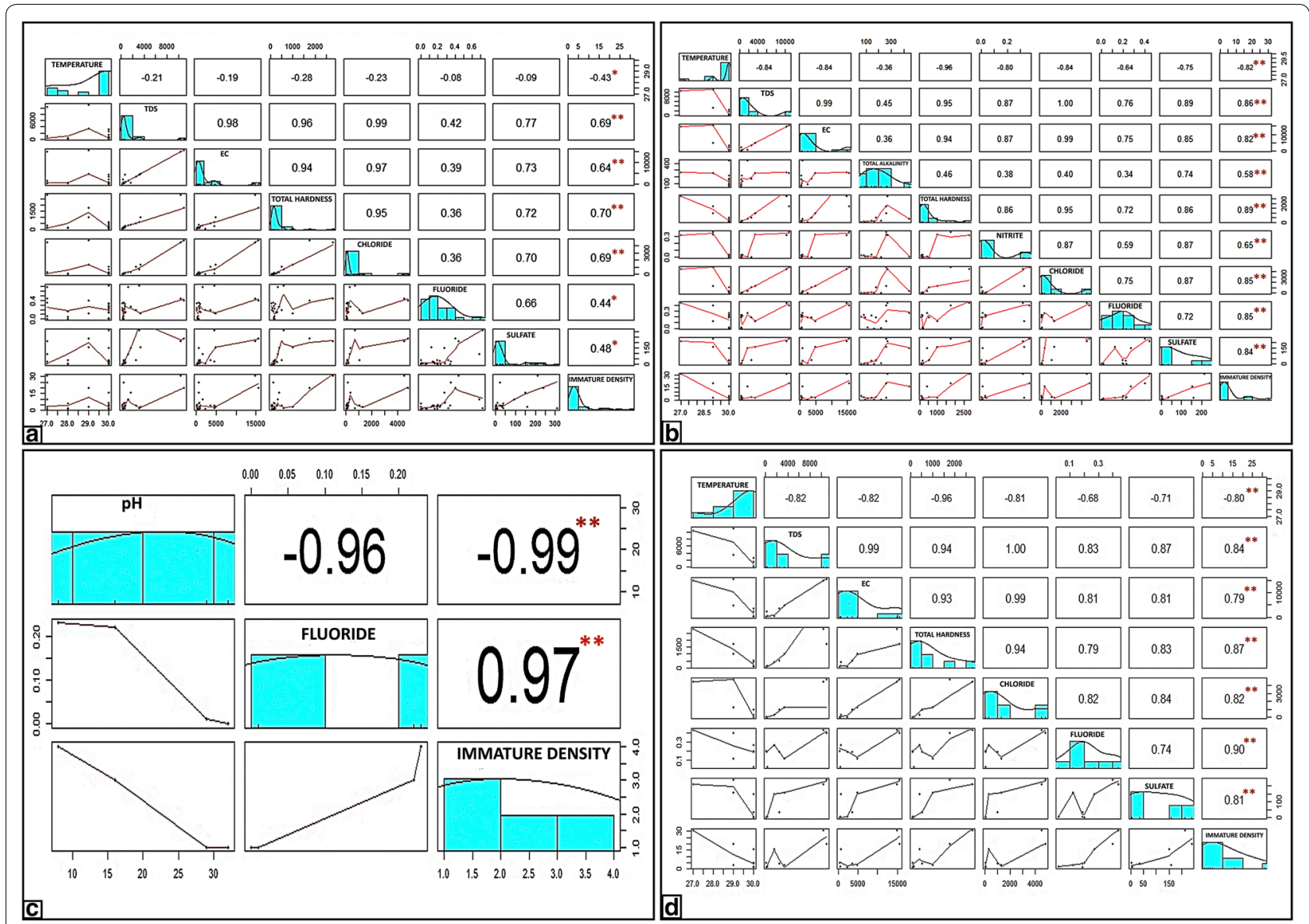

Fig. 2 The scatter plot matrix of physico-chemical parameters with significant correlation. Correlation of physico-chemical parameters with immature density: a in habitats where Anopheles co-bred with other mosquito species; $\mathbf{b}$ in habitats where Anopheles bred alone; $\mathbf{c}$ in wells where Anopheles bred alone; $\mathbf{d}$ in OHTs where Anopheles bred alone. The distribution of significant parameters are represented in the boxes along the diagonal line from extreme top left to extreme bottom right. Each parameter is plotted against the other below the diagonal line. These boxes display the bivariate scatter plots with a fitted line. The corresponding value of the correlation plus the significance level as stars $\left({ }^{*} p<0.05 ;{ }^{* *} p<0.01\right)$ are represented in the boxes above the diagonal. The $X$-axis values are given for each parameter either at the top or bottom alternatively in the Figure. Likewise, the $Y$-axis values are also given alternatively either at the left or right

equation for immature density was framed based on this model, i.e., Immature density $=21.070+0.002$ (TDS) $(15.867 *$ nitrite $)+(21.623 *$ fluoride $)+$ Error.

\section{Discussion}

The present study revealed that physico-chemical parameters of water have no impact on mosquito breeding in general except nitrite, which significantly differentiates habitats with mosquito breeding from those without mosquito breeding; nitrite was found to be higher in the latter (Table 1). Although nitrite showed no significant correlation with immature density in habitats with mosquito breeding in general (Fig. 2a), it had a significant positive correlation with immature density in habitats where Anopheles bred alone (Fig. 2b). Thus, An. stephensi seems to prefer less nitrite content whereas other species such as Culex sp. breeds in water with either high or low content of nitrite [16]. Similar observations were made in Kuwait [17] where An. stephensi preferred less nitrite content compared to Culex sp. and in Ghana where Anopheles gambiae preferred much less nitrite content $(<0.005 \mathrm{mg} / \mathrm{L})$ [18]. Furthermore, phosphate showed significant difference in habitats with Anopheles breeding and when co-inhabitation of Anopheles was observed with other mosquito species. It was found to be higher in the former, which explains higher phosphate content favouring Anopheles breeding, unlike other mosquito species. A strong positive correlation of phosphate with mosquito larval abundance was observed in Sri Lanka [19]; In Ethiopia it was observed that phosphate was positively correlated with Anopheles larvae [20], which is in concordance with the observations of the present study. 
The high values of phosphate, nitrite and nitrate were reported to be indicators of organic pollution [17, 21].

Six out of 15 parameters analysed in the present study: TDS, EC, total hardness, chloride, fluoride, and sulfate, had significant positive correlation with immature density in habitats with mosquito breeding in general, habitats with Anopheles bred alone and in OHTs where Anopheles bred alone [7, 22]. In contrast, these six parameters except fluoride did not show any significant correlation in wells where Anopheles bred alone whereas, $\mathrm{pH}$ had high significant negative correlation.

A number of studies done in various geographical locations around the world (Ethiopia, Kenya, Iran, Delhi) support the fact that temperature is positively correlated with Anopheles larval abundance [3, 7, 20, 23]. In Bangladesh [24] temperatures collected from meteorological departments had no correlation with Anopheles abundance, which is similar to earlier findings that meteorological data do not give an actual estimate of temperature-dependent traits [25]. In contrast, in the present study, temperature has a strong negative correlation with immature density of An. stephensi larvae in OHTs. Since temperature was recorded only at the time of inspection, variations and their impact cannot be taken into consideration as the objectives of the present study were to find any relation or association between physico-chemical variables with occurrence and abundance of An. stephensi.

Anopheline immatures have been reported to live in acidic [26] as well as alkaline medium [27]. However, alkaline $\mathrm{pH}$ with the range $8-8.5$ is considered to be favourable $\mathrm{pH}$ for the majority of anophelines [7]. In Iran [7], An. stephensi was found with $\mathrm{pH}$ ranging 7.1-8.6, which is similar to the present study, where anopheline positive breeding habitats exhibited $\mathrm{pH}$ from slightly acidic to alkaline (6.82-8.72). Further, similar to temperature, $\mathrm{pH}$ is believed to be positively correlated with Anopheles larval density $[23,28]$, whereas it has been reported that $\mathrm{pH}$ had no significant association with Anopheles density [29]. The present study revealed that although $\mathrm{pH}$ had no correlation with An. stephensi density in habitats where it bred alone or with other mosquito species, it had a strong negative correlation with An. stephensi immature density in wells where it bred alone.

The highlight of this study is the highly significant positive correlation of fluoride with Anopheles immature density. In Ghana An. gambiae showed significant positive correlation of fluoride $(\mathrm{r}=0.739, \mathrm{p}=0.036)$ with higher proportions of An. gambiae s.s. M-form in larval habitats [18]. In the present study, although fluoride showed significant weak positive correlation with immature density in general, fluoride along with TDS, EC, total hardness, chloride, and sulfate, indicated a very strong positive correlation in habitats where An. stephensi bred alone. Moreover, in OHTs fluoride had the highest positive significant correlation value $(r=0.90)$ among other significant parameters (TDS, EC, total hardness, chloride, sulfate). In the earlier study, OHTs had been discovered as the potential breeding habitat for An. stephensi in the same area [8]. Even in wells, fluoride had strong positive correlation with immature density of An. stephensi $(\mathrm{r}=0.97)$. Also when all the physico-chemical parameters were analysed together in a habitat with An. stephensi breeding, fluoride has significant difference on the immature density. Although it is revealed that higher fluoride content favours Anopheles breeding, in the present study it is well within the water quality standards as the range of fluoride concentration $(0-0.72 \mathrm{mg} / \mathrm{L})$ observed is not higher than Center for Disease Control (CDC)-recommended optimal fluoride concentration to community water systems, which is $0.7 \mathrm{mg} / \mathrm{L}$ [30]. The findings of strong positive correlation between fluoride and immature density of An. stephensi irrespective of the nature or type of breeding habitats, such as OHTs and wells, indicates its probable role as an oviposition attractant in luring gravid females of An. stephensi, unlike other mosquito species. Hence, fluoride can be considered as a predictor for urban vector breeding and would be an useful indicator for the presence of vector breeding. LSM by using conventional larvicides (Temephos) against urban malaria vectors is traditionally and routinely undertaken in all clear water habitats. In the present study, Urur-Olcott Kuppam, located northeast, and Odaima Nagar, at the southeast, both adjacent to the shore, consists of slum tenements with high prevalence of malaria (Fig. 1). The survey carried out in these two slum areas did not locate potential breeding habitats such as OHTs and wells. However, adjacent areas of these slums had breeding habitats contributing to the abundance and propagation of An. stephensi [12].

There are increasingly renewed interests globally to promote/advocate development of appropriate intervention tools to target malaria vector control in aquatic stages, especially in urban settings, where it is operationally difficult to target adult populations due to innumerable, hidden resting habitats where it can evade household repellents. In this context, potential habitats, such as OHTs, which produce significantly more adult vector mosquitoes, may eventually contribute towards malaria transmission and disease burden. It is important to identify such breeding habitats and target them with appropriate LSM to achieve the object of reducing urban malaria. The habitat characteristics observed in the present study can be used to further explore operational ways in which LSM can be focussed against urban malaria vectors. The application of such innovative intervention tools needs to be easy for operational field personnel to effectively identify the most productive 
potential breeding habitats. This method would ultimately help in arresting vector abundance as a long-term and permanent solution.

The limitation of this study is that the variation in fluoride concentration and vector density was not analysed. The sampling of physico-chemical parameters were comparatively less mainly because the analysis was outsourced and the study objective was limited to the occurrence of Anopheles breeding and its possible correlation with the physico-chemical parameters. In future, selection of a few important physio-chemical variables can be analysed to target more habitats to obtain a robust data which helps to develop a mathematical model which may be useful for situation based vector control interventions. Further, a year-long collection of water samples from sentinel and random sites were not carried out to find seasonal variations in physico-chemical parameters and their correlation to mosquito breeding and/or immature An. stephensi density. The present study describes the relationship between breeding habitats and physicochemical parameters, but not the causal association.

\section{Conclusion}

Control of immatures through source reduction and routine application of larvicides are considered to be key intervention tools in eliminating malaria. These measures are intended to reduce transmission of malaria by preventing propagation of vector mosquitoes and subsequently reducing vector-pathogen-human contact. Knowledge of larval vector ecology is a key factor in risk assessment and implementation of effective vector control operations. It may be argued that physico-chemical parameters in anopheline breeding habitats reflects the ovipositional preference or behaviour of these mosquitoes to identify the most appropriate from diverse breeding habitat environments in an urban settlement. Periodic seasonal analysis will help to give a vivid and broader picture of how the various parameters of breeding waters influence mosquito bionomics and population dynamics. The information thus obtained will help in proper planning of intervention measures for vector control programmes.

\section{Additional file}

Additional file 1: Table S1 Linear regression model for physico-chemical parameters and immature density.

\footnotetext{
Abbreviations

OHT: overhead tank; LSM: larval source management; TDS: total dissolved solids; BOD: biological oxygen demand; DO: dissolved oxygen; EC: electrical conductivity; TWAD: Tamil Nadu Water Supply and Drainage Board; CDC: Center for Disease Control; CMWSSB: Chennai Metropolitan Water Supply and Sewerage Board.
}

\section{Authors' contributions}

AE designed the experiment with input from MTM and NV. AE, ST, SR, JAJ, and AA participated in study design. ST and AE wrote the manuscript. JAJ, AA, ST, and SR collected water samples from the study site. MJK, SR, AA, and JAJ contributed to data analysis. All authors read and approved the final manuscript.

\section{Author details}

${ }^{1}$ IDVC Field Unit, National Institute of Malaria Research (ICMR), NIE Campus, 2nd Main Road, TNHB, Ayapakkam, Chennai 600 077, India. ${ }^{2}$ Department of Zoology, Madras Christian College, Tambaram, Chennai 600 059, India.

${ }^{3}$ National Institute of Malaria Research (ICMR), Sector 8, Dwarka, New Delhi 110 077, India.

\section{Acknowledgements}

We thank National Institute of Malaria Research and Indian Council of Medical Research for providing the necessary facilities and support. We gratefully acknowledge: Drs. Jane Carlton from New York University, USA and Matthew B Thomas from Penn State University for their valuable suggestions; Mr. E Elumalai and other staff of NIMR field unit, Chennai; technical staff of Regional office for Health and Family Welfare (Govt of India) at Besant Nagar, Chennai; the communities of Adyar, Besant Nagar, Thiruvanmiyur for permitting us to carry out immature vector and water sampling/collection in their premises. We are thankful to the authorities of Tamil Nadu Water and Drainage (TWAD) board of Govt of Tamil Nadu, where the physico-chemical analysis of water samples were carried out. The financial assistance from Council of Scientific and Industrial Research (Junior Research fellowship), New Delhi to ST for this study is thankfully recalled. This work was supported by the National Institute of Allergy and Infectious Diseases, National Institutes of Health (NIH) Grant U19A1089676. The content of this manuscript is solely the responsibility of the authors and does not necessarily represent the official views of the NIH. The manuscript has been approved by NIMR publication screening committee (No. 016/2016).

\section{Competing interests \\ The authors declare that they have no competing interests.}

\section{Availability of data and materials}

The dataset generated during and/or analysed during the current study available from the corresponding author on reasonable request.

\section{Ethics approval and consent to participate}

The manuscript does not involve the use of any animal or human data or tissue. However, institutional ethical clearance of the project was obtained from National Institute of Malaria Research of Indian Council of Medical Research, New Delhi (ECR/NIMR/EC/2010/100).

\section{Funding}

The work was supported by the National Institute of Allergy and Infectious Diseases, National Institutes of Health (NIH) Grant U19AI089676. The content of this manuscript is solely the responsibility of the authors and does not necessarily represent the official views of the $\mathrm{NIH}$. The financial assistance as Junior Research fellowship was provided to ST from Council of Scientific and Industrial Research, New Delhi.

Received: 21 August 2016 Accepted: 31 October 2016 Published online: 09 November 2016

References

1. Oyewole I, Momoh O, Anyasor G, Ogunnowo A, Ibidapo C, Oduola $\mathrm{O}$, et al. Physico-chemical characteristics of Anopheles breeding sites: impact on fecundity and progeny development. Afr J Environ Sci Tech. 2009:3:447-52.

2. Piyaratne MK, Amerasinghe FP, Amerasinghe PH, Konradsen F. Physicochemical characteristics of Anopheles culicifacies and Anopheles varuna breeding water in a dry zone stream in Sri Lanka. J Vector Borne Dis. 2005;42:61-7. 
3. Ndenga BA, Simbauni JA, Mbugi JP, Githeko AK. Physical, chemical and biological characteristics in habitats of high and low presence of Anopheline Larvae in Western Kenya Highlands. PLoS ONE. 2012;7:e47975.

4. Bashar K, Tuno N, Ahmed TU, Howlader AJ. Blood-feeding patterns of Anopheles mosquitoes in a malaria-endemic area of Bangladesh. Parasit Vectors. 2012;5:39.

5. Mutero CM, Ng'ang'a PN, Wekoyela P, Githure J, Konradsen F. Ammonium sulphate fertiliser increases larval populations of Anopheles arabiensis and culicine mosquitoes in rice fields. Acta Trop. 2004;89:187-92.

6. Robert V, Awono-Ambene HP, Thioulouse J. Ecology of larval mosquitoes, with special reference to Anopheles arabiensis (Diptera: Culicoidae) in market-garden wells in urban Dakar. Senegal. J Med Entomol. 1998;35:948-55.

7. Soleimani-Ahmadi M, Vatandoost H, Zare M. Characterization of larval habitats for anopheline mosquitoes in a malarious area under elimination program in the southeast of Iran. Asian Pac J Trop Biomed. 2014;4(Suppl 1):S73-80.

8. Thomas S, Ravishankaran S, Justin JA, Asokan A, Mathai MT, Valecha $\mathrm{N}$, et al. Overhead tank is the potential breeding habitat of Anopheles stephensi in an urban transmission setting of Chennai, India. Malar J. 2016;15:274.

9. Wanji S, Mafo FF, Tendongfor N, Tanga MC, Tchuente E, Bilong Bilong CE, et al. Spatial distribution, environmental and physicochemical characterization of Anopheles breeding sites in the Mount Cameroon region. J Vector Borne Dis. 2009;46:75-80.

10. WHO. Manual on practical entomology in malaria: methods and techniques. Geneva: World Health Organization. Division of malaria other parasitic diseases, part 2; 1975.

11. Guidelines of entomological surveillance of malaria vectors in Sri Lanka, Anti malaria campaign. 2009. http://www.malariacampaign.gov.lk/downloads/revised\%20guidelines\%20for\%20entomological\%20surveillance. pdf. Accessed 27 Jan 2016.

12. WHO. Larval source management: a supplementary measure for malaria vector control: an operational manual. Geneva: World Health Organization; 2013. pp 69-70.

13. Nagpal BN, Sharma VP. Indian anophelines. New Delhi: Oxford and IBH Publishing Co., Pvt Ltd; 1995.

14. Nagpal BN, Srivastava A, Saxena R, Ansari MA, Dash AP, Das SC. Pictorial identification key for Indian anophelines. Delhi: Malaria Research Centre (ICMR); 2005.

15. American Public Health Association (APHA). Standard methods for the examination of water and wastewater. 21st ed. Washington DC: APHA 2005

16. Kenawy M, Ammar S, Abdel-Rahman H. Physico-chemical characteristics of the mosquito breeding water in two urban areas of Cairo Governorate, Egypt. J Entomol Acarol Res. 2013;45:17.
17. Salit A, Al-Tubiakh S, El-Fiki S, Enan O, Wildey K. Physical and chemical properties of different types of mosquito aquatic breeding places in Kuwait State. In: Wildey KB, editor. Proceedings of the second international conference on urban pests-ICUP. Edinburgh: UK; 1996. p. 185-93.

18. Kabula BI, Attah PK, Wilson MD, Boakye DA. Characterization of Anopheles gambiae sl and insecticide resistance profile relative to physicochemical properties of breeding habitats within Accra Metropolis, Ghana. Tanzan J Health Res. 2011;13:163-87.

19. Kirinde G, Wegiriya H. Mosquito larval survey and their correlation with some chemical parameters in selected water bodies in Matara, Sri Lanka. J Zool Stud. 2015:2:5.

20. Feltelius V, Elleby R. Habitat characterization for malaria vector mosquito larvae in Gamo Gofa, Ethiopia. 2014

21. Amerasinghe FP, Indrajith NG, Ariyasena TG. Physico-chemical characteristics of mosquito breeding habitats in an irrigation development area in Sri Lanka. Cey J Sci (Biol Sci). 1995;24:13-29.

22. Kipyab PC, Khaemba BM, Mwangangi JM, Mbogo CM. The physicochemical and environmental factors affecting the distribution of Anopheles merus along the Kenyan coast. Parasit Vectors. 2015:8:221.

23. Verma AK, Dhiman RC, Singh RK, Das MK. A longitudinal study on Anopheles mosquito larval abundance in distinct geographical and environmental settings and emergence in Ranchi and Ramgarh of Jharkhand. CIBTech J Microbio. 2015;4:13-8

24. Bashar K, Tuno N. Seasonal abundance of Anopheles mosquitoes and their association with meteorological factors and malaria incidence in Bangladesh. Parasit Vectors. 2014;7:442.

25. Cator LJ, Thomas S, Paaijmans KP, Ravishankaran S, Justin JA, Mathai MT, et al. Characterizing microclimate in urban malaria transmission settings: a case study from Chennai, India. Malar J. 2013;12:84.

26. Adebote DA, Oniye SJ, Muhammed YA. Studies on mosquitoes breeding in rock pools on inselbergs around Zaria, northern Nigeria. J Vector Borne Dis. 2008;45:21-8.

27. Dejenie T, Yohannes M, Assmelash T. Characterization of mosquito breeding sites in and in the vicinity of tigray microdams. Ethiop J Health Sci. 2011;21:57-66.

28. Berti J, Gonzalez J, Navarro-Bueno E, Zoppi E, Gordon E, Delgado L. Larval seasonality of the mosquito Anopheles aquasalis (Diptera: Culicidae) and other insects associated to its habitat in Sucre, Venezuela. Rev Biol Trop. 2010;58:777-87.

29. Animut A, Gebre-Michael T, Balkew M, Lindtjorn B. Abundance and dynamics of anopheline larvae in a highland malarious area of southcentral Ethiopia. Parasit Vectors. 2012:5:117.

30. Public US. Health service recommendation for fluoride concentration in drinking water for the prevention of dental caries. Public Health Rep. 2015;130:318-31.

\section{Submit your next manuscript to BioMed Central and we will help you at every step:}

- We accept pre-submission inquiries

- Our selector tool helps you to find the most relevant journal

- We provide round the clock customer support

- Convenient online submission

- Thorough peer review

- Inclusion in PubMed and all major indexing services

- Maximum visibility for your research

Submit your manuscript at www.biomedcentral.com/submit
BioMed Central 